\title{
Improved Diagnosis of Pulmonary Tuberculosis using Bleach (Sodium hypochlorite) Concentration Technique at Tertiary Care Hospital
}

\author{
Saroj Kumar Thakur, ${ }^{1}$ Vishvesh Prakashchandra Bansal, ${ }^{2}$ Jyotsna Mishra, ${ }^{3}$ \\ M.P.Bansal, ${ }^{4}$ Iswari Sapkota, ${ }^{5}$ Tapeshwar Yadav ${ }^{6}$ \\ ${ }^{1-4}$ Department of Microbiology, MGM Medical College, Aurangabad, Maharashtra, India; \\ ${ }^{5}$ Divine Pathology and Diagnostic Centre, Janakpur Dham, Dhanusha, Nepal; \\ ${ }^{6}$ Department of Laboratory Medicine, Madan Bhandari Academy of Health Sciences, Hetauda, Nepal.
}

\begin{abstract}
Introduction: In Revised National Tuberculosis Control Program (RNTCP), microscopic examination of sputum for acid fast bacilli (AFB) is currently the backbone for diagnosis of pulmonary tuberculosis. Studies have shown liquefaction and concentration of sputum by $5 \%$ sodiumhypochlorite is useful in providing increased sensitivity and safety for handling of specimen.

Objective: To assess the utility of $5 \%$ Sodium hypochlorite concentration method in increasing the sensitivity of smear microscopy for detection of AFB for diagnosis of pulmonary tuberculosis.

Methods: The study included a total of 1000 sputum samples from 500 patientsof suspected pulmonary tuberculosis. Direct smears were prepared from the sputum samples as per RNTCP guidelines. Remaining sputum was used for bleach concentration and smears prepared from the concentrated material. Both smears were stained by Ziehl-Neelsen staining and screened for acid fast bacilli and graded according to the RNTCP guidelines.

Results: A total of 158 samples (15.8\%) from 89 patients were positive by routine direct method where as by concentration method 236 samples (23.6\%) from 143 patients were found positive diagnosing additional 54 patients. The gain in sputum smear positivity of $7.8 \%$ over routine method is highly significant $\left(p=0.0000, \chi^{2}=270\right)$ with a $10.8 \%$ increase in case detection.

Conclusions: Improvement in the sensitivity of smears microscopy will be useful in case detection of tuberculosis especially in resource poor countries. The increased positivity of microscopy by bleach method indicates that would prove useful if included in the RNTCP to improve case detection.
\end{abstract}

Keywords: Concentration; smear positivity; sodium hypochlorite; tuberculosis.

\section{INTRODUCTION}

Tuberculosis (TB) persists as a major cause of human morbidity and mortality, affecting almost 9.4 million and causing 1.8 million deaths yearly worldwide. ${ }^{1}$ India accounts for nearly one third of

\footnotetext{
Correspondence

Saroj Kumar Thakur

Email : sarojt823@gmail.com

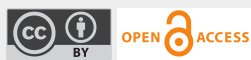

Citation

Thakur SK, Bansal VP, Mishra J, Bansal MP, Sapkota I, Yadav T. Improved Diagnosis of Pulmonary Tuberculosis using Bleach (Sodium hypochlorite) Concentration Technique at Tertiary Care Hospital. Nepal J Health Sci. 2021 Jul-Dec; 1(2): 15-22.
}

the global burden of tuberculosis. ${ }^{2}$ It is estimated that about $40 \%$ of Indian population is infected with TB bacillus. ${ }^{3}$ Estimated global prevalence of the disease is $139 / 100,000$ population. ${ }^{4}$ The disease was declared a global emergency by World Health Organization since $1993^{5}$ and Revised National Tuberculosis Control Programme (RNTCP) pilot began. ${ }^{6}$ In RNTCP microscopic examination of sputum for AFB plays an important role in the initial diagnosis of tuberculosis. In the last decade, many researchers have suggested that the performance of sputum smear microscopy can be significantly improved if sputum is liquefied using $\mathrm{NaOCl}$ and then concentrated by either centrifugation or 
sedimentation prior to staining. ${ }^{7}$ This procedure also disinfects the sputum within 30 minutes without destroying the acid fastness of the mycobacterium tuberculosis. With this background, we planned our study to assess the utility of sodium hypochlorite concentration method in increasing the sensitivity of smear microscopy for diagnosis of pulmonary tuberculosis.

\section{METHODS}

The cross-sectional study was carried out in Department of Microbiology from January 2014 to June 2014 at Tertiary Care Center. A total 1,000 sputum samples (one morning and one spot) from 500 patients with age group between 10 to 90 years were collected from Revised National Tuberculosis Control Programme (RNTCP) center from

- Suspected pulmonary tuberculosis patients with cough for two weeks or more duration.

- Follow up patients already under anti-tubercle drug treatment.

Sputum samples were collected in a disposable, clean, wide mouth, sterile, leak-proof screw-capped plastic containers clearly labeled with patient's identification number andwere processed as follows.

\section{Direct Method:}

For the direct smears mucopurulent portion of sputum was taken on a new, clean and grease free slide, smear was prepared heat fixed and stained by $\mathrm{ZN}$ stainingaccording to RNTCP guidelines using $25 \% \mathrm{H}_{2} \mathrm{SO}_{4}$ as a decolorizer. ${ }^{8}$

\section{Bleach Method:}

From the remaining part of the sputum $2 \mathrm{ml}$ of sputum was taken in screw caped centrifuge tubes. Equal volume of 5\% sodium hypochlorite was added to the test tube and kept at room temperature for half an hour. The test tube was shaken intermittently, after which $8 \mathrm{ml}$ of distilled water was added to the test tube and centrifuged at $5000 \mathrm{rpm}$ for 20 minutes.
The supernatant was carefully discarded and smears were prepared from the sediment andheat fixed. The smears were stained similarly as by direct method. Smears prepared by both the methodswere graded as per RNTCP criteria.

Known positive and negative sputum specimen were included in every batch specimen processed. To remove the observer bias, slides prepared by both the methods were observed and graded by two experienced investigators separately by bright field microscopy. The two investigators read the slide independently and were blinded to each other's results. Where there was a discrepancy in grading, slides were re-examined by both readers together and a consensus grade was reached.

Testing for viability of $M$. tuberculosis after Bleach decontamination:

This was done to test whether the bacteria remained viable and capable of causing infection after 30 minutes treatment with $5 \%$ bleach.Five samples with $3+$ grading were cultured on Lowenstein Jensen (L-J) medium after concentration by $5 \%$ bleach and incubated at $37^{\circ} \mathrm{C}$ for eight weeks. The same samples were also decontaminated by $4 \% \mathrm{NaOH}$ (Petroff's method) ${ }^{9}$ and cultured on Lowenstein Jensen (LJ) medium and incubated at $37^{\circ} \mathrm{C}$ for eight weeks. Along with Five samples with $3+$ grading, positive control and negative control sample are also cultured on Lowenstein Jensen (L-J) medium and incubated at $37^{\circ} \mathrm{C}$ for eight weeks.

All the data was managed in Microsoft Excel and statistical analysis was done using Epi-info. Pearson's Chi-square test was used for comparative evaluation between two groups.

\section{RESULTS}

Out of 1000 samples from 500 patients 158 (15.8\%) were positive and $842(84.2 \%)$ were negative by direct method, whereas by bleach concentration method $236(23.6 \%)$ were positive and 764 (76.4\%) were negative. There was an increase of 78 
Table 1: Comparison of results of samples by Direct and Bleach concentration.

\begin{tabular}{|l|c|c|}
\hline \multirow{2}{*}{} & Direct method & Bleach method \\
\cline { 2 - 3 } & Positive & Negative \\
\hline Positive & $158(15.8 \%)$ & $236(23.6 \%)$ \\
\hline Negative & $842(84.2 \%)$ & $764(76.4 \%)$ \\
\hline Total & 1000 & 1000 \\
\hline
\end{tabular}

( $p=0.001, \chi 2=607$, statistically highly significant $)$

Table 2: Positivity of Direct and bleach method's sample wise and according to acid fast bacilli (AFB) grading.

\begin{tabular}{|c|c|c|c|c|c|}
\hline \multirow{2}{*}{ AFB Grading } & \multicolumn{5}{|c|}{ Direct Method } \\
\cline { 2 - 6 } & Spot & Morning & Total & Gain Spot & GainMorning \\
\hline $3+$ & 21 & 21 & 42 & - & - \\
\hline $2+$ & 08 & 12 & 20 & - & 04 \\
\hline $1+$ & 38 & 37 & 75 & 01 & - \\
\hline Scanty & 08 & 13 & 21 & - & 05 \\
\hline Total & $\mathbf{7 5}$ & $\mathbf{8 3}$ & $\mathbf{1 5 8}$ & $\mathbf{0 1}$ & $\mathbf{0 9}$ \\
\hline \multirow{2}{*}{ AFB Grading } & Spot & Morning & Total & Gain Spot & GainMorning \\
\hline \multirow{2}{*}{$3+$} & 21 & 21 & 42 & - & - \\
\hline $2+$ & 08 & 13 & 21 & - & 05 \\
\hline $1+$ & 49 & 44 & 93 & 05 & - \\
\hline Scanty & 36 & 44 & 80 & - & 08 \\
\hline Total & $\mathbf{1 1 4}$ & $\mathbf{1 2 2}$ & $\mathbf{2 3 6}$ & $\mathbf{0 5}$ & $\mathbf{1 3}$ \\
\hline
\end{tabular}

samples by bleach method. The gain in positivity of bleachmethod was $7.8 \%$, which was statically highly significant $(p=0.0000, \chi 2=607)$. All smears positive by direct method were also positive by bleach method. There was no sample which was positive by direct method and negative by bleach method. (Table 1)

Of 158 samples positive by direct method, 75 were spot and 83 were morning samples. Similarly out of the 236 positive samples by bleach method 114 were spot and 122 were morning samples. The overall difference in gain of morning samples is 8 by both methods i.e. $1.6 \%$. There were 75 spot samples positive by direct method as compare to 114 by bleach method. Thus there was gain of $39(7.8 \%)$ spot samples by bleach method. There were 83 morning sample positive by direct method as compare to 122 by bleach method. Thus there was gain of $39(7.8 \%)$ morning samples by bleach method. (Table 2 and Figure 1)

For Sputum samples with high concentration of acid-fast bacilli $(3+$ and $2+$ ), positivity was similar for both the method, that is 62 by direct method and 63 by bleach method. For sputum with low concentration of bacilli (1+ and scanty) the bleach method was superior method to identify positives. For sputum with grading $1+$, the bleach method was superior method detecting 93 positive as compare to 75 bydirect method. For sputum with scanty grading the bleach method was superior method detecting 80 as compared to 21 by direct method. Both in the direct and bleach method in the samples with grading of $2+$ and scanty the positivity was more in the morning samples. The gain in the positivity in morning samples for direct method was 9 samples (four, $2+$ and five, scanty) and for bleach method 
Table 3: Sputum Smear Grading according to Revised National Tuberculosis Control Program (RNTCP) guidelines.

\begin{tabular}{|l|c|c|c|}
\multicolumn{1}{|c|}{ Examination } & Result & Grading & $\begin{array}{c}\text { No. of fields should be } \\
\text { examined }\end{array}$ \\
\hline >10 AFB per oil immersion field & $+\mathrm{ve}$ & $3+$ & 20 \\
\hline 1-10 AFB per oil immersion field & $+\mathrm{ve}$ & $2+$ & 50 \\
\hline 10-99 AFB per oil immersion field & $+\mathrm{ve}$ & $1+$ & 100 \\
\hline 1-9 AFB per oil immersion field & Scanty & Record exact number seen & 100 \\
\hline No AFB per 100 oil immersion field & $-\mathrm{ve}$ & & 100 \\
\hline
\end{tabular}

were 13 samples (five, $2+$ and eight, scanty). For the samples grading $1+$ both in direct and bleach method, the spot samples showed a higher positivity. The gain in positivity was one sampleby direct method andfive samples by bleach method. (Table 2)

We have graded the smears for both direct and bleach method according to the RNTCP guidelines into negative, scanty, $1+, 2+$ and $3+.{ }^{1}$ (Table 3 )

After analyzing the grading, we found a marked increase in the average number of AFB seen per microscopic field in the smear prepared after concentration by bleach method as compared to direct method or the grading remained the same (e.g. smears which were graded scanty or $1+$ by direct method became $2+$ or $3+$ by bleach method). There was no sample which scored a lower grading by bleach method as compare to direct method.
We had studied 1,000 samples from 500 patients (2 samples each). Out of which 158 samples were positive by direct method identifying 89 patients having tuberculosis. Similarly out of 1,000 samples 236 were positive by bleach method identifying 143 patients. Thus bleach concentration technique identified 54 (10.8\%) more patients. The difference is statistically highly significant ( $p=0.0000$, $\chi 2=270$ ). Eighty-nine patients that were positive by direct method were also positive by bleach method. There were no patients positive by direct method and negative by bleach method. The 357 patients were negative by direct method were also negative by bleach method. (Table No. 4). Additional 54 patients positive only by bleach method, out of which 24 patients-initiated treatment, 9 are follow up patients are already on treatment, 2 are relapse cases, 11 patients were not initiated treatment and 8 are referred outside.

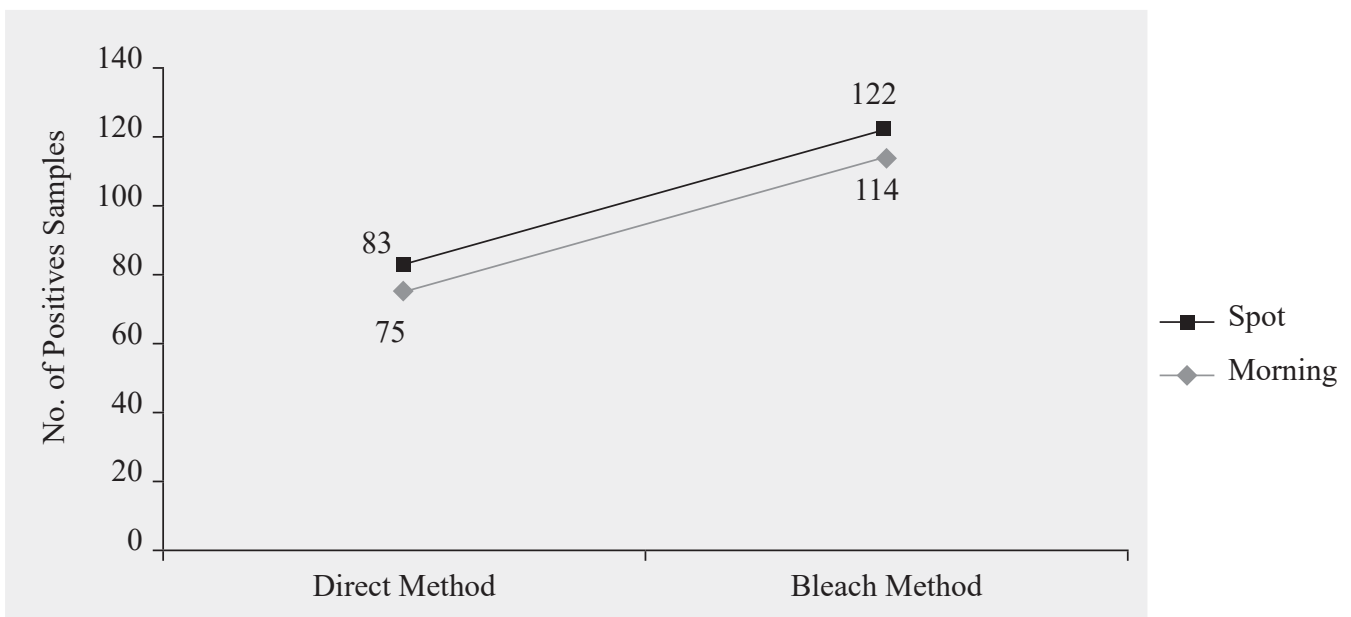

Figure 1: Line graph showing Positivity of morning and spot samples with different methods. 
Table 4: Comparison of results of patients by Direct and Bleach method.

\begin{tabular}{|l|c|c|}
\hline \multirow{2}{*}{} & Direct method & Bleach method \\
\cline { 2 - 3 } & Positive & Negative \\
\hline Positive & $89(17.8 \%)$ & $143(28.6 \%)$ \\
\hline Negative & $411(82.2 \%)$ & $357(71.4 \%)$ \\
\hline Total & 500 & 500 \\
\hline
\end{tabular}

$(p=0.0000, \chi 2=270$, statistically highly significant $)$

Result of viability of M. tuberculosis after Bleach decontamination:

The five known 3+ graded positive sample treated with 5\% bleach did not show any growth on the Lowenstein Jensen (L-J) medium, whereas the samples treated by Petroff's method gave growth of M. tuberculosis. This indicated that the mycobacteria were killed during concentration with bleach method. Hence, we have proved the safety of $\mathrm{NaOCl}$ treated sample by testing the viability of the bacilli by culture on the Lowenstein Jensen (L-J) medium. The bacilli failed to grow indicating complete disinfecting of the samples.

\section{DISCUSSION}

Proper identification of a case of tuberculosis is of utmost importance in the Revised National Tuberculosis Control Programme (RNTCP). Direct microscopy of sputum is the backbone of diagnosis in this programme. Direct smear is also helpful in the monitoring the treatment of patients. It is easy to perform, replicable, rapid and cheap method for screening suspects for diagnosing tuberculosis patients for treatment. It is specific but not a very sensitive test. ${ }^{7}$ Negative smears do not exclude the diagnosis of tuberculosis as about $55 \%$ of pulmonary tuberculosis cases worldwide harbors low bacillary load. ${ }^{2}$ Culture is the gold standard and more sensitive than direct smear microscopic, but it is time consuming and laborious and GeneXpert is sensitive but, costly. ${ }^{10}$ Hence these techniques are not commonly done for screening of patients for tuberculosis and facilities for culture are not available everywhere.

Studies have shown that digesting and concentrating sputum with $5 \% \mathrm{NaOCl}$ (Bleach) increases the yields of sputum smear microscopy., ${ }^{2,4,5}$ The present studies aim at assessing the performance of this method in increasing the yield of smear positive cases. It was compared to the direct method on 1,000 sputum samples from 500 patients (one morning and one spot).
The present studies showed increased positivity by bleach method identifying $236(23.6 \%)$ positive samples as compared to $158(15.8 \%)$ by the direct method. Gain in the smear positivity of $7.8 \%$ is statistically highly significant $(p=0.0000)$. The bleach method thus significantly increases case detection. Similar gain in positivity of $7.11 \%$ was reported by Kaore et al. ${ }^{2}$

In the smears graded $3+$ and $2+$ the difference in positivity by the two methods was negligible ( 62 by direct method and 63 by bleach method). However in the smears graded $1+$ and scanty the bleach method identified significantly more positives ( 96 by direct method and 173 by bleach method). This indicates that bleach method was very useful in samples with less number of bacilli and thus will be of great help in identifying cases with paucibacillary samples.

By both the methods the positivity was more in the morning samples. The gain in positivity in morning samples bydirect methodas well as bleach method was eight samples. But there was one sample graded $1+$ by the direct method which was positive in spot but negative in morning. Similarly there were five samples graded $1+$ by the bleach method positive in spot but negative in morning. There is no explanation for this discrepancy of results in the samples graded 1+. Therefore according to this finding, if only morning samples would have 
been taken,one sample by direct method and five cases by bleach method would have been remained undetected. Thus testing of single sample would result in missing of cases of tuberculosis. Therefore Revised National Tuberculosis Control Programme (RNTCPs) protocol of collecting two samples per patients is justified.

There was a substantial gain in positivity in the spot and morning samples by the bleach method. Positivity in thespot samples increased from 75 to 114 and for morning samples from 83 to 122 . This can be attributed to concentration of bacteria during bleach concentration process and clearing of background debris making the acid fast bacilli easily detectable.

There was also a marked increased in the average number ofacid fast bacilli seen per field after concentrating the samples e.g. samples with grading of negative, scanty, 1+ by direct method showed a higher grading of $1+, 2+$ and even $3+$ by bleach method. This again is because of the digestion/ liquefaction of the viscid sputum, concentrating the bacteria and clearing of debris surrounding the bacteria making them easily visible.Thus in case of paucibacillary specimen chances of false negative reporting will be minimized. In few very thick samples we required additional time for proper decolorization as some black particles developed in the samples on treatment with hypochlorite. These created some blotches in the smears but this did not hamper the concentration of bacilli or its staining properties. This is our experience and no other studies have reported a similar experience. We do not have definite explanation for this. Mindolli et a ${ }^{11}$ has said that overheating the slide may result in the formation of hydroxide crystals which may put a compromise on the readings. Such crystal formation was not experienced in the present study. We had no experience of our smears becoming fragile and getting washed off during staining. Mindolli et a ${ }^{11}$ and Hepple et $\mathrm{al}^{4}$ experienced bleach method made the smear fragile and easily washed out during staining. Hepple et $\mathrm{al}^{4}$ attempted to prevent this with the addition of bovine serum albumin, but smears were difficult to decolorize and discontinued the practice.

The bleach method detected 143 cases of tuberculosis as compared to 89 cases detected by direct method. Thus bleach method identified additional 54 cases $(10.8 \%)$ which is statistically highly significant $(p=0.0000)$ gain in case detection. All patients positive by directmethod were also positive by bleach method which supports the validity of bleach digested smears. We have followed the additional 54 patients' positive only by bleach method for clinical management (Table 5). Treatment decisions were based on the results of direct smear microscopy of two sputum samples and $\mathrm{x}$-ray findings i.e. according to Revised National Tuberculosis Control Programme (RNTCP) criteria. Treatment decisions were not based on the results of the bleach concentration method.

Twenty-four patients had $\mathrm{x}$-ray suggestive of tuberculosis and according to guidelines of Revised National Tuberculosis Control Programme (RNTCP) were labeled pulmonary tuberculosis smear negative (new cases). These cases were put on anti-tubercular drug treatment. Out of these 24 patients 16 patients had two smear positive (32 smear) showing grading of scanty for 27 smears and $1+$ for 5 smears. Remaining 8 were one smear positive showing grading of scanty for 6 smears and $1+$ for 2 smears.

Nine patients were new cases that had came for follow up, of which 4 patients ( 8 smears) were two smears positive and all had scanty grading. Five patients were one smear positive of which 4 were graded $1+$ and one was graded scanty.

Two patients were relapse cases that had came for follow up and wereone smear positive with a grading of $1+$ and $2+$.

Eleven patients had negative x-ray finding and did not receive anti-tuberculartreatment. Of this all were one smear positive, with grading of $1+$ for 2 smears and scanty for 9 smears. It cannot be said whether 
Table 5: Evaluation of additional 54 patients diagnosed by Bleach method

\begin{tabular}{|c|c|c|c|c|}
\hline $\begin{array}{l}\text { Additional Patients } \\
\text { diagnosed over } \\
\text { RNTCP }(\mathrm{n}=54)\end{array}$ & $\begin{array}{l}\text { Status by } \\
\text { RNTCP } \\
\text { method }\end{array}$ & $\begin{array}{l}\text { Status by Bleach method } \\
\text { ( } n=\text { number of smear) }\end{array}$ & $\begin{array}{l}\text { Grading } \\
\text { in Bleach } \\
\text { method }\end{array}$ & Remarks \\
\hline \multirow[b]{2}{*}{24} & \multirow{2}{*}{$\begin{array}{c}\text { Smear } \\
\text { Negative }\end{array}$} & $\begin{array}{l}2 \text { smear Positive, } 16 \text { patients } \\
(32 \text { smears) }\end{array}$ & $\begin{array}{l}5 / 32-1+ \\
27 / 32-\text { Scanty }\end{array}$ & $\begin{array}{l}\text { X-ray Positive Treatment } \\
\text { initiated. }\end{array}$ \\
\hline & & $\begin{array}{l}1 \text { smear Positive, } 8 \text { patients } \\
\text { (8 smears) }\end{array}$ & $\begin{array}{l}2 / 8-1+ \\
6 / 8-\text { Scanty }\end{array}$ & $\begin{array}{l}\text { X-ray Positive Treatment } \\
\text { initiated. }\end{array}$ \\
\hline \multirow[b]{2}{*}{09} & \multirow{2}{*}{$\begin{array}{c}\text { Smear } \\
\text { Negative }\end{array}$} & $\begin{array}{l}2 \text { smear Positive, } 4 \text { patients } \\
\text { (8 smears) }\end{array}$ & 8/8 - Scanty & $\begin{array}{l}\text { Follow up patients already on } \\
\text { treatment. }\end{array}$ \\
\hline & & $\begin{array}{l}1 \text { smear Positive, } 5 \text { patients } \\
(5 \text { smears })\end{array}$ & $\begin{array}{l}4 / 5-1+ \\
1 / 5-\text { Scanty }\end{array}$ & $\begin{array}{l}\text { Follow up patients already on } \\
\text { treatment. }\end{array}$ \\
\hline 02 & $\begin{array}{c}\text { Smear } \\
\text { Negative }\end{array}$ & $\begin{array}{l}1 \text { smear Positive, } 2 \text { patients } \\
(2 \text { smears })\end{array}$ & $\begin{array}{l}1 / 2-1+ \\
1 / 2-2+\end{array}$ & Relapse case \\
\hline 11 & $\begin{array}{l}\text { Smear } \\
\text { Negative }\end{array}$ & $\begin{array}{l}1 \text { smear Positive, } 11 \text { patients } \\
\text { (11 smears) }\end{array}$ & $\begin{array}{l}2 / 11-1+ \\
9 / 11-\text { Scanty }\end{array}$ & $\begin{array}{l}\text { X-ray Negative Treatment not } \\
\text { initiated. }\end{array}$ \\
\hline \multirow[b]{2}{*}{08} & $\begin{array}{c}\text { Smear } \\
\text { Negative }\end{array}$ & $\begin{array}{l}2 \text { smear Positive, } 4 \text { patients } \\
(8 \text { smears })\end{array}$ & $\begin{array}{l}4 / 8-1+ \\
4 / 8-\text { Scanty }\end{array}$ & $\begin{array}{l}\text { Outside referred Patients lost } \\
\text { Follow up. }\end{array}$ \\
\hline & $\begin{array}{c}\text { Smear } \\
\text { Negative }\end{array}$ & $\begin{array}{l}1 \text { smear Positive, } 4 \text { patients } \\
(4 \text { smears })\end{array}$ & 4/4 - Scanty & $\begin{array}{l}\text { Outside referred Patients lost } \\
\text { follow up. }\end{array}$ \\
\hline
\end{tabular}

these patients are true positive as the results cannot be validated by culture in the present study. But these cases are likely to be true positive in a country where the annual risk infection is as great as $3 \% .^{12}$

Eight patients were outside referred from private practitioner and could not be followed or traced. Of these 4 patients were two smears positive ( 8 smears) with grading of $1+$ for 4 smears and scanty for 4 smears. The remaining 4 patients were one smear positive, all were graded scanty. They might have received treatment outside our RNTCP centre.

Use of sodium hypochlorite for concentration of sputum is technically easy to perform and not very laborious process. It can be done with the same technical team and will require very little additional expenses. Additionally it requires screw-caped centrifuge tubes, centrifuge machine and sodium hypochlorite. Sodium hypochlorite is cheap and available everywhereas household bleach. Gebre et al (1995) described that relative centrifugal force needed for sedimentation of mycobacteria was lower after digestion with $\mathrm{NaOCl}$ and the necessary relative force can be achieved by low cost table top centrifuge or even by hand driven model. ${ }^{13}$ Another important advantage of this method is that the bacilli will not remain viable on 30 minutes exposure to $\mathrm{NaOCl}$ and pose no risk of infection to the handlers. This will make the lab technician feel safe. We have proved the safety of $\mathrm{NaOCl}$ treated sample by testing the viability of the bacilli by culture on the Lowenstein Jensen (L-J) medium. The bacilli failed to grow indicating complete disinfecting of the samples. Similar findings were reported by Rattan et al using $1 \% \mathrm{NaOCl}$. They also stated that exposure time of 15 minutes was sufficient to kill the mycobacteria using $1 \% \mathrm{NaOCl}$. According to him $1 \% \mathrm{NaOCl}$ would also be effective in killing HIV safeguarding the health care worker from HIV infection. ${ }^{14}$

The bleach method requires additional time of approximately one hour. So the result of bleach method can be given on the same day that is along with the result of direct method. Also the samples that are collected for the direct method can be used 
for the bleach method. After the smears for direct method are made the remaining sputum samples can be used for concentration method.

One of the approaches to minimize the work load would be to do bleach concentration on one of the samples only that is either spot or morning as per experience of laboratories. In our study morning samples had higher positivity, so we recommend the morning samples would be a better sample for concentration. Also generally it is advocated to preferably collect morning sputum samples for better diagnosis. ${ }^{9}$ In the study by Kaore et al spot sample had higher positivity. ${ }^{2}$ Another approaches would be to test only those samples negative by the direct method. Thus still reducing of the number of samples to be processed by concentration method. From the gain in smear positivity by bleach method in the present study we believe that tuberculosis control programme should consider the use of bleach concentrated smears in their case detection activities.

\section{CONCLUSIONS}

Improvement in the sensitivity of smears microscopy will be useful in case detection of tuberculosis especially in resource poor countries. The increased positivity of microscopy by bleach method indicates that is would prove useful if included in the RNTCP to improve case detection. The technique required additional sodium hypochlorite which is cheap and easily available. Also centrifuge tubes and machine will be required which are not very expensive. The significant gain of $10.8 \%$ in the case detection by bleach method definitely compensates for the additional cost and efforts. It is safe technique and kills the bacilli during the process of concentration with no risk of infection to handler.

\section{Conflict of Interest: None}

\section{SUMMARY}

This is a cross-sectional study conducted in 1,000 sputum samples. The authors report that increased positivity of microscopy by bleach method indicates that would prove useful if included in the RNTCP to improve case detection. The authors were able to identify it is safe technique and kills the bacilli during the process of concentration with no risk of infection to handler.

\section{NJHS}

\section{REFERENCES}

1. Bharatwaj RS, Mangaiyarkarasi T, Jeyakumari D, Rajaram P. The adequacy of two sputum smear examinations for diagnosis of Pulmonary Tuberculosis as per RNTCP- A Retrospective study in Pondicherry. Int J Med Health Sci. 2012;1(2):17-22.

2. Kaore NM, Date KP, Thombare VR. Increased sensitivity of sputum microscopy with sodium hypochlorite concentration technique: A practical experience at RNTCP centre. Lung India 2011;28(1):17-20.

3. TB India Revised National TB Control Programme: annual status report.Central TB Division, Directorate General of Health Services. 2012 . p. 3-8.

4. Hepple P, Nguele P, Greg J, Bonnet M, Sizaire V. DirectMicroscopy versus sputum cytology analysis and bleach sedimentation for diagnosis of tuberculosis: a prospective diagnostic study. BMC Infectious Disease. 2010;10(276):1-7.

5. Makunde WH, Makunde RA, Kamugisha LM, Megma SG, Liwa A. Improved Microscopy Diagnosis of pulmonary tuberculosis using sodium Hypochlorite concentration technique in Tanga, Tanzania. Tanzania Health Research Bulletin. 2007;9(2):87-93.

6. Revised National TB Control Programme. Traning Module for Medical Practitioner. Central TB Division, Directorate General of Health Services. 2010. p. 2-17.

7. Githui WA, Matu SW, Muthami LN, Juma E. Improved Diagnosis of ZN smear negative tuberculosis using Sodium Hypochlorite sedimentation method. East Afr Med J. 2007;28(10):455-459.

8. Revised National Tuberculosis Control Programme (RNTCP). Manual for Laboratory Technician. Central TB Division, Directorate General of Health Services. 1997. p. 1-14.

9. Watt B, Aayrer A, Haris G (eds). Mycobactreia. In: Collee JG, Fraser AG, BP Marmion, Simmons A (eds). Mackie andMcCarteny Practical Microbiology. 14thedi. Churuch Livingstone.Elisevier; 2006. p. 329-342.

10. Yassin MA., Cuevas LE. Gebrexabher H. Squire SB Efficacy and safety of short-term bleach digestion of sputum in case-finding for pulmonary tuberculosis in Ethiopia. Int J Tuberc Lung Dis. 2003;7(7):678-683.

11. Mindolli PB, Salmani MP, Parandekar PK. Improved diagnosis of pulmonary tuberculosis using bleach microscopic method.J Clin Diagn Res. 2013;7(7):1-3.

12. Chakraborty AK. Epidemiology of tuberculosis: Current status in India. Indian J Med Res. 2004;120:248-276.

13. Gibre N, Karlsson Ulf, Jonsson G, Macaden R, Wolde A, Assefa A et al. Improved microscopical diagnosis of pulmonary tuberculosis in developing countries. Transactions RSTMH. 1995; 89(2):191-193.

14. Rattan A, Kishore K, Singh S, Jaber M, Xess I, Kumar R. Evaluation of a safe sputum processing method for detecting tuberculosis. J Clin Pathol. 1994 ; $47: 41$ 1-413. 